\title{
GERAKAN TRANSNASIONAL ISLAM DAN GLOBALISASI SALAFI DI ISLAMIC CENTER BIN BAZ YOGYAKARTA
}

\author{
Abd. Rachman Assegaf \\ Universitas Islam Negeri Sunan Kalijaga Yogyakarta \\ Email : profassegaf@gmail.com
}

\begin{abstract}
This study tries to elaborate critically the globalized Salafi and its transnational movement with specific cases in Islamic Center Bin Baz (ICBB) of Yogyakarta. It focuses on how the institute modernized their education and propagation (dakwa) movements within global contexts. Its roles in globalized Salafi and persisted core values are inherent in the middle of globalization impacts. The research method applied in this study is cultural studies and field studies with data collection techniques of triangularily taken from documentation, interview and observasion. ICBB Yogyakarta, to some extend, applied modern information and communication technology to introduce and draw attention to transnational Islam. From inception, transnational linkage between ICBB and the Middle Eastern education, especially Makkah and Madinah ulamas and universities, had been linked since the establishment of the institute. Some ICBB's students are come from surrounding villagers but the others from foreign countries such as Thailand, Singapore and Malaysia. On the other hand, Islamic traditional cultures, values and tenets are also manifested in daily life of whole pesantren communities in spite of modernization and globalization influences. Identities, like the way of live, clothes, foods and beverages, and ethical behaviors of these Salafi movements could easily be typically recognized, whereas that performance indicated the persistence of its values towards globalization and modernization. ICBB Yogyakarta represents adaptive position towards global changes and not anti-Government stands or involves directly in practical politics. This study intentionally elaborates the origins and pattern of globalized salafi at ICBB.
\end{abstract}




\section{الملخص}

تسعى هذه الدراسة إلى وضع نقدي للسلفية المعولمة و حركتها عبر الوطنية مع حالات محددة في المركز الإسلامي بن باز بيوجياكارتا. و يركزعلى كيفية تحديث المعهد

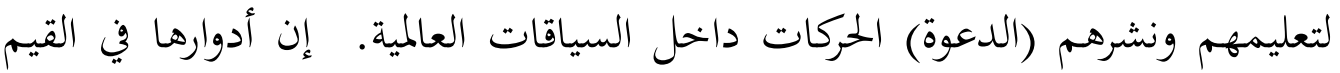
السلفية المعولمة والقيم الأساسية الثابتة هي متأصلة في وسط آثار العولمة. طريقة البحث المطبقة في هذه الدراسة هي الدراسات الثقافية والدراسات الميدانية مع تقنيات جمع البيانات ثلاثية المثلث المأخوذة من الوثائق والمقابلات والمراقبات. المركز الإسلامي بن باز بيوجياكارتا ، إلى حدما، يطبق تكنولوجيا المعلومات و الاتصالات الحديثة لإدخال ولفت الانتباه إلى الإسلام عبر الوطنية. منذ البداية، تم ربط الربط عبر الوطنية

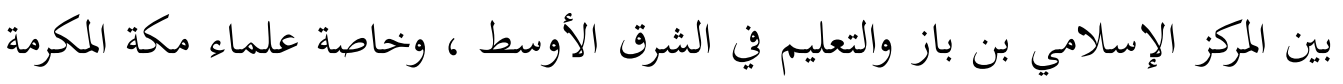

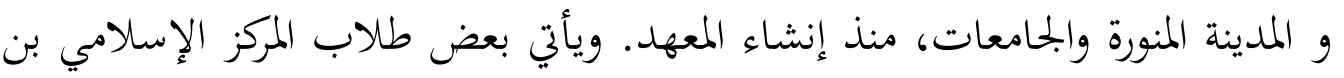
باز من قرويين محيطيين ولكن الآخرين من بلدان أجنبية مثل تايلاند وسنغافورة و ماليزيا. ومن ناحية أخرى، تتجلى الثقافات والقيم والمبادئ التقليدية الإسلامية في ترني

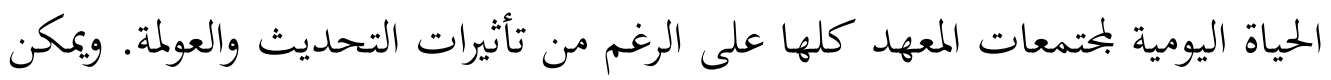
بسهولة تعرفهم على الهويات، مثل طريقة العيش والملابس والأطعمة والمشروبات والسلوكيات الأخلاقية لهذه الحركات السلفية، في حين أن هذا الأداء يشير إلى استمرار قيمها نحو العولمة و التحديث. المركز الإسلامي بن باز بيوجياكارتا يمثل

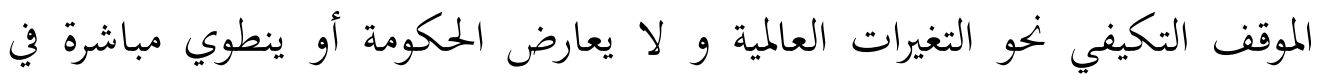

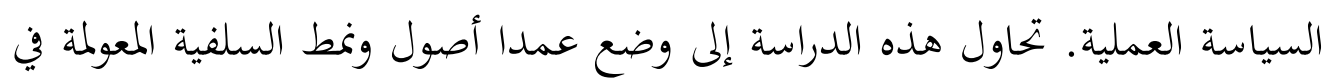
المركز الإسلامي بن باز.

Keywords : Salafi, Transnasional Islam, Globalisasi, Islamic Center Bin Baz 


\section{A. Pendahuluan}

Islam jelas merupakan agama transnasional, baik dari segi doktrin teologis maupun legal fiqhiyyah, yang melintasi batas-batas kabilah, suku, bangsa, ras dan seterusnya. Islam adalah agama bagi seluruh umat manusia yang beragam dari berbagai segi. Jika ada perbedaan yang ditekankan doktrin Islam di tengah berbagai realitas transnasional tersebut, maka itu adalah ketaqwaan belaka. Tidak ada bedanya antara individu dan kelompok Muslim dengan lainnya, kecuali hanyaketaqwaannya - ketundukan dan kepasrahan sepenuhnya kepada Allah SWT. Pada saat yang sama, sebagai realitas sejarah yang melintasi waktu dan tempat, Islam juga sekaligus menjadi realitas lokal. Islam hidup di tengah lingkungan masyarakat atau lokalitas tertentu, dan karenanya tidak imun dan bebas dari berbagai pengaruh faktor dan kekuatan sejarah tertentu. Karena itu pada gilirannya doktrin-doktrin Islam yang semula bersifat transnasional tersebut kemudian dalam batas tertentu mengalami proses kontekstualisasi, vernakularisasi, dan bahkan indigenisasi. Melalui proses seperti inilah Islam dalam perjalanan sejarahnya bukan hanya merupakan agama transnasional, tetapi sekaligus juga menjadi realitas lokal. ${ }^{1}$

Dalam konteks ini perlu dipertegas pemaknaan gerakan transnasional. Gerakan transnasional dipahami sebagai kelompok keagamaan yang memiliki jaringan internasional. Kelompok atau gerakan keagamaan tersebut datang kesuatu negara dengan membawa paham keagamaan (ideologi) baru dari negeri seberang (Timur Tengah) yang dinilai berbeda dari paham keagamaan lokal yang lebih dahulu eksis. ${ }^{2}$ Salah satu kelompok keagamaan transnasional Islam yang telah mengglobal tersebut adalah salafi.

Globalisasi salafi memungkinkan terjadi karena kuatnya desakan zaman akibat proses modernisasi teknologi komunikasi berbasis digital dan elektronik seperti komputer dengan jaringan internet, Wi Fi, Hot Spot, dan telepon seluler, serta kemudahan sarana transportasi antar daerah, kota, bahkan Negara. Ini menyebabkan gelombang gerakan salafi kian menjangkau lintas bangsa dan

\footnotetext{
1 Azyumardi Azra, "Muhammadiyah: Tantangan Islam Transnasional" dalam Maarif: Arus Pemikiran Islam dan Sosial, 100 Tahun Muhammadiyah: Civil Society dan Tantangan Gerakan Islam Transnasional (Yogyakarta: Maarif, Vol.4 No.2 Tahun 2009), hal.14-15.
}

2 Lihat Suhanah, Gerakan Dakwah Salafi di Indonesia, hal.215. 
Negara, atau transnasional. Gerakan transnasional Islam yang dilakukan oleh kelompok salafi tetap menjaga nilai tradisional-konservatifnya, namun menarik ulur dengan kemajuan zaman, sehingga mereka mampu memanfaatkan jasa modernisasi tersebut dan menjadikan gerakannya mengglobal.

Gerakan salafi sendiri sebenarnya mudah dikenali dari performance atau tampilan yang nampak dari luar, mengingat adanya perbedaan praktis dalam kehidupan sehari-hari dan bermasyarakat. Pakaian, tampilan tubuh, serta gaya hidup kaum salafi cenderung back to basic, atau meneladani al-salaf al-shalih terhadap nilai-nilai keagamaan, sehingga cara berpakaian mereka mengikuti sedekat-dekatnya pada masa kejayaan umat Islam di zaman klasik, mulai dari masa Nabi SAW hingga sahabat dan tabi'in yang dipandang sebagai khair alqurun atau sebaik-baik masa. Meskipun perkembangan arus global saat ini diwarnai dengan berbagai mode pakaian yang beragam, namun pendukung salafi tetap mampu bertahan melanjutkan karakter tradisional-konservatif tersebut, baik bagi kalangan pria maupun wanitanya.

Menariknya, gerakan transnasional salafi ini muncul di lembaga pendidikan Islam madrasah atau pesantren. Ibarat wadah, madrasah, pesantren, ataupun Islamic Center, maka gerakan salafi di atas merupakan bibit yang subur bersemai dan menemukan tempatnya. Di beberapa madrasah dan pesantren di Indonesia, masih dijumpai tipologi gerakan salafi ini yang eksis dan terus berkembang di tengah arus globalisasi. Bahkan globalisasi tersebut tidak menghalangi bertahannya nilai-nilai salafi, justu dampak globalisasi tadi diolah menjadi bagian dari proses globalisasi salafi.

Perkembangan global memiliki dampak tertentu bagi kehidupan beragama. Arus global bisa menimbulkan turbulensi bagi keberagamaan umat. Global berarti mendunia. Jadi, turbulensi arus global dimaksudkan sebagai pergolakan yang ditimbulkan akibat modernisasi di segala bidang yang telah mendunia. Pengaruh arus global ini amat luas, dan tidak terlewatkan pula imbasnya pada keberagamaan umat. ${ }^{3}$ Karena globalisasi, langsung atau tidak, dapat membawa paradoks bagi praktek keberagamaan umat, seperti terjadinya gejala kontramoralitas antara apa yang diidealkan dalam pendidikan (das solen) dengan realitas di lapangan (das sein), maka mencermati arus globalisasi ini hendaknya

3 Sudarwan Danim, Agenda Pembaruan Sistem Pendidikan, (Yogyakarta: Pustaka Pelajar, 2003), hal.64. 
tidak terjebak pada posisi kawan maupun lawan bagi arus globalisasi, melainkan bersikap arif, bijak, dan selektif, tanpa menghilangkan karakter keberagamaan umat itu sendiri. Mastuhu berpendapat bahwa menutup diri atau bersikap eksklusif akan ketinggalan zaman, sedang membuka diri berisiko kehilangan jati diri atau kepribadian. ${ }^{4}$

Di antara lembaga pendidikan Islam yang menyemaikan nilai-nilai salafi sekaligus melakukan upaya transnasional Islam melalui gelombang globalisasi dimaksud adalah Islamic Center Bin Baz (ICBB), Piyungan, Yogyakarta. ICBB membuktikanbahwanilai-nilaikeagamaanIslamyangmurnidapatdilaksanakan di zaman modern dan di tengah arus globalisasi. Bila diperhatikan dengan seksama, pesantren salafi ini mampu menjangkau komunitas setempat, bahkan lingkup nasional dan transnasional, sebagaimana terlihat dari keberadaan peserta didiknya yang berasal dari mancanegara, terutama Asia Tenggara, seperti Indonesia, Malaysia, Thailand, Brunei Darussalam, dan lainnya. Buku teks dan referensi yang digunakan sebagai bahan pembelajarannya pun bukan hanya berbahasa Indonesia atau Malaysia, melainkan Arab, Melayu dan Jawa. Sering dijumpai bahwa alumni mereka menyebar ke lintas daerah dan mancanegara sehingga membentuk jaringan transnasional.

Tulisan ini difokuskan pada kajian terhadap gerakan transnasional Islam dan globalisasi salafi di ICBB Yogyakarta karena kemampuannya memelihara nilai-nilai Islam murni, dan kemampuan memodernisir gerakannya di tengah arus globalisasi. Ini tergolong unik, mengingat tidak semua pesantren, madrasah maupun Islamic Center mampu bertahan menghadapi tantangan globalisasi yang kian deras sehingga justru terseret ke dalam pusaran arus globalisasi, lalu identitasnya pun berubah. Selain itu, telaah ini juga bermaksud membahas apa dan bagaimana nilai-nilai Islam murni serta gerakan transnasional Islam yang dikembangkan oleh ICBB. Secara umum, tujuan pembahasan ini adalah untuk menganalisis pola gerakan salafi ICBB dalam memodernisir gerakan Islam, dan bukan untuk fokus kajian pada dimensi normatif yang sering diklaim sebagai fundamentalisme, radikalisme ataupun garis keras. Problem akademik yang hendak ditemukan jawabannya adalah bagaimana asal usul dan bentuk-bentuk globalisasi salafi yang berkembang di ICBB.

4 Mastuhu. Menata Ulang Pemikiran Sistem Pendidikan Nasional dalam Abad 21, (Yogyakarta:Safiria Insania Press, 2003), hal.126. 


\section{B. Profil Ringkas ICBB}

Pondok Pesantren ICBB adalah lembaga pendidikan di bawah naungan Yayasan Majelis At-Turots Al-Islamy Yogyakarta. Pondok pesantren ini sudah dirintis sejak tahun 1993 dengan nama Ma'had Tahfizhul Quran. Pada tahun 1996 kegiatan yang sebelumnya berlokasi di Sedan, Sariharjo, Ngaglik, Sleman lalu dipindah ke Ma'had Jamilurrahman yang beralamat di Glondong Sawo Banguntapan Bantul.5 Seiring dengan selesainya pembangunan lokal kelas dan asrama di Karanggayam, Sitimulyo, Piyungan, Bantul pada tahun 2000, kegiatan Ma'had Tahfizhul Quran dipindah dari Ma'had Jamilurrahman ke lokasi baru ini. Di sinilah mulai digunakan nama Islamic Centre Bin Baz dan diselenggarakan pendidikan diniyah Islamiyah dan pendidikan umum secara terpadu.

Tiga tahun kemudian, tepatnya pada tahun 2003, ICBB ditetapkan oleh Departemen Agama sebagai penyelenggara program wajib belajar pendidikan dasar 9 tahun (Wajar Dikdas). Tingkat SD disebut dengan Salafiyah Ula (SU) dan tingkat SMP disebut Salafiyah Wustha (SW). Dengan program ini lulusan SU dan SW ICBB, selain mendapatkan ijazah pondok, akan mendapatkan ijazah resmi dari pemerintah. Terhitung sejak 2010, jenjang pendidikan setingkat SMA yaitu Madrasah Aliyah ICBB telah menjadi lembaga pendidikan formal. Dan pada tahun 2012 telah mendapatkan akreditasi peringkat A dari Badan Akreditasi Nasional Sekolah/Madrasah untuk program IPA dan Keagamaan. Selain itu satu tahun sebelumnya yaitu pada tahun 2011 Ijazah pondok mendapatkan mu'adalah (Akreditasi) dari Universitas Islam Madinah, Saudi Arabia. Dalam bidang Tahfizh Al-Quran, pada tahun 2011 ICBB membuka Ma'hadz Tahfizh khusus untuk mempersiapkan calon pengajar tahfizh yang bersanad dan berijazah.6 Hasil dari pendidikan tahfizh ini cukup menggembirakan, karena dibuktikan dengan banyaknya prestasi lomba tahfizh yang diraih oleh para santri. Di bagian depan dari pintu masuk ke kantor ICBB terdapat lemari yang berisi berbagai piala dan penghargaan lomba tahfizh ini, baik tingkat regional, propinsi, nasional maupun internasional.

5 Hal ini sesuai pula dengan hasil wawancara dengan bagian administrasi ICBB, Ustadz Turino, pada Kamis 17 September 2015 di kantor bagian informasi.

6 Lihat profil Islamic Center Bin Baz (ICBB) dalam www.binbaz.or.id sebagaimana diakses pada 23 Agustus 2015. 
Secara jelas visi lembaga ICBB ini termaktub dalam lingkungan pesantren dan dapat diketahui oleh umum melalui websitenya, dimana lembaga ICBB ini memilikivisimenjadi lembaga pendidikan bertaraf internasionalyang bermanhaj salaf dalam berakidah, bermuamalah dan berakhlak. Dari visi tersebut kemudian dijabarkan dalam beberapa poin misi, yaitu: 1 . Mencetak generasi rabbani yang berpegang teguh kepada Al-Quran dan As-Sunnah sesuai pemahaman Salafus Shalih; 2. Mendidik generasi yang mampu menghadapi tantangan global dan mampu memberikan kontribusi penyelesaian masalah umat dengan dilandasi akhlak mulia; 3. Mendidik generasi penghafal Al-Quran yang memahami pokok-pokok agama dan beradap kepada Allah, Rasul-Nya, orang tua, sesama manusia dan makhluk secara umum, serta mampu berbahasa Arab baik tulisan, bacaan, maupun percakapan; 4 . Menyelenggarakan pendidikan resmi dengan kurikulum diniyah dari Timur Tengah dan kurikulum umum nasional yang mendapatkan 2 ijazah yang diakui baik oleh Pemerintah maupun lembaga pendidikan di Timur Tengah; 5. Menciptakan suasana dan lingkungan yang berbahasa Arab dan Islami di lingkungan ICBB. ${ }^{7}$

ICBB tergolong berkembang dengan pesat. Lokasinya berada di Jalan Wonosari Km.10, Karanggayam, Sitimulyo, Piyungan, Bantul, Yogyakarta 55792. Telepon/Faksimile 0274-4353272 website: www.binbaz.or.id. Lokasi lembaga tersebut walaupun berada di pinggir kota, yakni sekitar $10 \mathrm{~km}$ keluar dari Ring Road Timur Yogyakarta, namun berada dalam lingkungan Kecamatan yang cukup ramai dan padat. Di sebelah pensantren ini terdapat SMA Negeri, SD Negeri, Kantor Kelurahan dan pemukiman penduduk dimana di sepanjang jalan raya banyak dijumpai pertokoan. Interaksi sosial masyarakat sekitar dengan pesantren ini cukup intensif karena terikat dengan kegiatan keagamaan yang sering melibatkan pihak pesantren. Selain itu, dilihat dari segi partisipasi masyarakat terhadap sekolah yang berada di bawah naungan ICBB yang tinggi, menunjukkan besarnya public trust terhadap pesantren ini.

Keberadaan ICBB di Piyungan sebenarnya sudah ada sejak tahun 90an akhir, dan mulai melebarkan sayap dengan membangun berbagai fasilitas sejak tahun 2007. Awalnya, ICBB hanya membangun sebuah pondok di daerah Dusun Karanggayam, dan sejak tahun 2007 mereka mulai membangun institusi pendidikan mulai dari Pendidikan Anak Usia Dini (PAUD) hingga Perguruan

\footnotetext{
7 Ibid.
} 
Tinggi (PT). Namun demikian, ternyata tidak semua warga sekitar mendukung perluasan pesantren ICBB karena dianggap kurang sosialisasi, tidak melibatkan warga, tidak memberi dampak peningkatan ekonomis, serta menimbulkan masalah sanitasi yang kurang baik. Kepala Dukuh Karangploso, Sukahar mengakui ada sejumlah warga dusunnya yang menolak. Hanya saja dari sekitar 210 Kepala Keluarga (KK) hanya 30\% yang melakukan penolakan. ${ }^{8}$

Hingga saat ini pesantren ICBB menyelenggarakan berbagai jenjang pendidikan, yaitu: pendidikan pra sekolah yang meliputi TPA, PAUD,TK dan $\mathrm{KB}$, pendidikan setingkat SD dengan lama pendidikan 6 tahun yang disebut dengan Salafiyah Ula (SU), pendidikan setingkat SLTP dengan lama pendidikan 3 tahun yang disebut dengan Salafiyah Wustha (SW), program penyiapan bahasa Arab bagi para calon santri Madrasah Aliyah yang berasal dari luar ICBB dengan lama belajar 1 tahun, pendidikan setingkat SMA dengan lama pendidikan 4 tahun, yakni 3 tahun belajar di kelas dan 1 tahun masa pengabdian, serta pendidikan penyiapan pengajar Al-Qur'an (khusus putra) dengan lama pendidikan 2 tahun (berijazah dan bersanad).

Keberhasilan pendidikan di pesantren ICBB tak lepas dari tenaga pendidiknya yang berkualitas dan didukung oleh fasilitas yang memadai. Kegiatan pendidikan di ICBB ditangani oleh para pendidik yang merupakan alumni Perguruan Tinggi di Saudi Arabia, Mesir, Pakistan, LIPIA, Universitasuniversitas ternama di Indonesia, alumni Pondok Pesantren Salaf, dan lainlain. Dari tahun ke tahun ICBB senantiasa melakukan peningkatan mutu pendidik, salah satunya melalui workshop-workshop kependidikan yang diselenggarakan secara rutin dan berkesinambungan. Dalam bidang Tahfizh dan Qiro'atul Quran, santri ICBB dibimbing oleh para pengajar yang memiliki Sanad dan Ijazah. Para tenaga pendidik pesantren ICBB tersebut bukan hanya kompeten dalam hal pengetahuan, melainkan suasana yang dikondisikan oleh para pendidik di lingkungan pesantren ini seakan merajut tali temali antara teori dengan praktek, antara ilmu dan amal. Semua itu dibentuk secara sosial dalam berbagai kegiatan, terutama shalat berjamaah di Masjid.

8 Erfanto Linakung, "Perluasan ICBB Ditolak Warga Piyungan" dalam Koran Sindo, Senin 28 September 2015. 
Sedang fasilitas pendukungnya mencakup beberapa sarana prasarana, yaitu:

a. Perpustakaan, laboratorium IPA, komputer, multimedia dan bahasa.

b. Minimarket di dalam lingkungan pondok.

c. Fasilitas olahraga: kolam renang, lapangan futsal, basket, sepak takraw, volley \& bulu tangkis.

d. SMS Centre dan Sistem Informasi Pondok berbasis Web untuk mengakses informasi nilai, SPP, kesehatan, presensi santri, dll.

e. Lingkungan pondok yang bersih dan asri serta masyarakat yang kondusif.

f. Perawatan di rumah sakit milik sendiri (RS At-Turots Al-Islamy).

g. Majalah Fatawa sebagai sarana informasi dan komunikasi antara wali santri dan pondok.

h. Radio Rodja (Radio Dakwah Ahlussunnah wal Jamaah).

Selain fasilitas di atas, di pesantren ICBB disediakan berbagai alternatif kegiatan ekstrakurikuler yang dapat diikuti oleh para santri, di antaranya adalah: Olah Raga dan Bela Diri Wushu, Komputer (Hardware \& Software), Tata Busana, Menyulam \& Keterampilan tangan, Tata Boga/Memasak, dan kegiatan ekstrakurikuler jurnalistik. Kegiatan ekstrakurikuler ini bersifat pilihan dan dilaksanakan di luar jam pelajaran dengan penyesuaian waktu yang beragam antara satu kegiatan dengan kegiatan yang lain. Agaknya beragam kegiatan ekstrakurikuler tersebut membawa hasil diraihnya berbagai macam kejuaraan dari lomba tingkat provinsi, nasional, maupun internasional.

\section{Gerakan Transnasional Islam Salafi di ICBB}

Gerakan salafi muncul pertama kali pada akhir abad ke-19 (sembilan belas) di Saudi Arabia. Pengaruh Saudi Arabia mengalir ke Indonesia melalui Dewan Dakwah Islamiyah Indonesia (DDII). Sekembalinya para alumni LIPIA yang telah menuntaskan studinya di Saudi Arabia tersebut menandai kelahiran generasi Wahabi baru di Indonesia, diantaranya adalah Abu Nida, Ahmad Faiz Asifuddin dan Aunur Rafiq Gufron sebagai kader DDII. ${ }^{9}$

9 Ibid., hal 216. 
Terkait dengan gerakan transnasional salafi di sini perlu dikemukakan lebih lanjut relevansinya dengan DDII dan LIPIA. DDII didirikan pada $9 \mathrm{Mei}$ 1967 yang merupakan sebuah organisasi yang bergerak di bidang keagamaan, pendidikan, informasi umat, dan sosial serta pelatihan para da'i. Lembaga ini diketuai oleh tokoh besar Masyumi, M. Natsir. Lembaga ini secara konsisten melakukan kegiatan dakwah ke pelosok-pelosok dengan mengirimkan kaderkadernya untuk mendakwakan Islam dan mencegah terjadinya Kristenisasi. Lembaga inilah yang nantinya akan menghasilkan tokoh-tokoh gerakan dakwah salafi di masa berikutnya. ${ }^{10}$ Para aktor-aktor salafi mendirikan yayasan serta mengembangkan kegiatannya menggunakan jaringan yang mereka miliki. Jaringan tersebut bersifat informal dan terbangun antara kader-kader DDII dan para alumnus Timur Tengah. Hal tersebut bisa kita lihat dari semua yayasan yang didirikan oleh para alumni Timur Tengah terutama dari Universitas Islam Madinah dan Universitas Islam di Riyadh. Selain itu untuk memuluskan kegiatannya mereka juga memanfaatkan jaringan DDII. ${ }^{11}$ Bagaimana dengan LIPIA?

LIPIA didirikan oleh Pemerintah Saudi Arabia pada tahun 1980 dengan nama Lembaga Pengajaran Bahasa Arab (LPBA). Pada awalnya hanya mengajarkan kursus-kursus bahasa Arab secara reguler kepada para siswanya. Baru di tahun 1986 LPBA resmi berganti akronim menjadi LIPIA (Lembaga Ilmu Pengetahuan Islam dan Bahasa Arab) setelah membuka program syariah. Di Indonesia lembaga ini berafiliasi dengan DDII dan beberapa organisasi Islam seperti Al Irsyad dan Persis. Sehingga dalam perjalanannya banyak kaderkader dakwah dari DDII yang belajar di lembaga ini termasuk dari kalangan salafi. LIPIA setidaknya memiliki dua peran strategis sekaligus bagi gerakan dakwah salafi. Pertama, lembaga ini secara penuh memberikan penguatan nilai dan ideologi bagi perkembangan dakwah salafi di Indonesia. Kedua, lembaga ini adalah lembaga yang mencetak aktor-aktor dari gerakan dakwah salafi untuk menyebarkan pemahaman salafi ke seluruh lapisan masyarakat. Dua hal tersebut yang mengantarkan gerakan dakwah salafi ideologinya terus direproduksi hingga saat ini. ${ }^{12}$ Pada awalnya LIPIA berpusat di Jakarta, dimana

10 Dady Hidayat, Gerakan Dakwah Salafi di Indonesia, hal.60-61.

11 Ibid., hal.86.

12 Dady Hidayat, Gerakan Dakwah Salafi di Indonesia, hal.87. 
pelajar Indonesia yang berminat untuk belajar di LIPIA harus menjalani seleksi terlebih dahulu. Bilamana lulus maka ia berhak studi di LIPIA dan mendapatkan beasiswa dengan berbagai fasilitasnya. Namun, perkembangan selanjutnya LIPIA membuka beberapa cabang di Indonesia, di antaranya adalah di Masjid Sunan Ampel Surabaya.

Relevan untuk disebutkan pula dalam pembahasan ini adalah bahwa $\mathrm{Abu}$ Nida, sebagai pimpinan ICBB saat ini, merupakan salah satu di antara alumni LIPIA yang telah menyelesaikan studinya di Saudi Arabia dan mengembangkan gerakan Wahabi generasi baru di Indonesia. Abu Nida termasuk kader DDII yang mengajar di beberapa pesantren seperti Pesantren al-Mukmin, Ngruki, Pesantren Wathaniyah Islamiyah, Kebumen dan Pesantren al-Furqan Gresik. Berbeda dengan pesantren NU, pesantren tersebut berciri modern namun ideologinya dekat dengan paham Wahabi. Perlu dicatat juga di sini bahwa penekanan kurikulumnya adalah pada bahasa Arab, ideologi Islam dan Fiqh. ${ }^{13}$ Para alumni Saudi Arabia atau negara Timur Tengah lainnya tersebut umumnya memiliki komitmen untuk mengembangkan paham Wahabi di bawah bendera Salafi dakwah. Mereka menyatakan bahwa umat Islam Indonesia amat memerlukan pemahaman yang benar terhadap apa yang dipraktikkan oleh ulama salaf al-shalih. Abu Nida lah yang berinisiatif mengembangkan gerakan salafi dakwah.

Abu Nida dilahirkan di Lamongan, Jawa Timur, pada tahun 1954. Setelah menyelesaikan sekolahnya di Pendidikan Guru Agama Muhammadiyah di Karangasem beliau tertarik mengikuti pelatihan dakwah DDII yang diselenggarakan di Pesantren Darul Falah Bogor di bawah kerangka dakwah mubaligh Muslim dalam program transmigrasi. Beliau dikirim ke pedalaman Kalimantan Barat, lalu Muhammad Natsir merekomendasikannya untuk belajar di Saudi Arabia. Beliaupun belajar bahasa Arab di LIPIA sebelum berangkat ke Universitas Imam Muhammad ibn Saud dari tahun 1979 sampai 1984 yang disponsori oleh Rabithah al-Alam al-Islami. Sambil belajar hukum Islam, beliau bekerja sebagai anggota staf di kantor cabang DDII di Riyadh dan berhubungan dengan para penyandang dana. Sebelum kembali ke tanah air, dia berjuang di

${ }^{13}$ Lihat Noorhaidi, Lasykar Jihad: Islam, "Militancy and the Quest for Identity in Post New Order Indonesia" dalam Disertasi dalam bentuk pdf. (Belanda: Universiteit Utrecht, 2005), hal.45. 
perang Afghanistan dan bergabung dengan faksi Jamaat al-Dakwah ila al-Qur'an wa al-Hadits yang dipimpin oleh Jamil al-Rahman. ${ }^{14}$ Sekembalinya ke tanah air ia mulai berdakwah salafi. Pesantren ICBB dan Ihyausunnah adalah di antara pesantren yang menerima donatur besar dari Yayasan Ihya al-Turats melalui Lajna Khairiyah di Jakarta. Setelah selesai proyek bantuan tersebut diterima, maka pesantren tadi harus menyiapkan laporan proyeknya. ${ }^{15}$

Abu Nida giat memberi ceramah di forum studi Islam yang diorganisir oleh jamaah setempat dan mempromosikan doktrin Wahabi kepada para mahasiswa. Beliau juga aktif dalam kegiatan halaqah dan daurah yang diselenggarakan oleh para aktivis gerakan Tarbiyah yang dikenal dekat dengan Ikhwan al-Muslimin. Beliau memperkenalkan slogan "aqidah salafi manhaj ikhwani" yang populer di kalangan para aktivis pada akhir tahun 1980an. ${ }^{16} \mathrm{Abu}$ Nida mendirikan Yayasan As-Sunnah pada tahun 1992 dengan melibatkan Ja'far Umar Thalib dkk, yang kemudian segera menjadi pusat kegiatan salafi yang terpenting di Indonesia. Melalui yayasan tersebut, kegiatan dakwah dan pembentukan halaqah dan daurah diarahkan untuk mempromosikan gerakan salafi. Akibatnya, kian banyak mahasiswa perguruan tinggi yang bergabung dalam aktivitas dakwah. Menyadari hal tersebut, Abu Nida dkk menerbitkan majalah As-Sunnah pada tahun 1994 yang merupakan terbitan salafi pertama di Indonesia. Majalah tersebut menyampaikan doktrin Wahabi dan fatwa keagamaan ulama Saudi Arabia tentang berbagai hal. Pada tahun yang sama, 1994, Abu Nida mendirikan Yayasan Majlis al-Turast al-Islami denggan slogan untuk mengajak umat Islam kembali ke jalan Islam yang benar (tashdiq a-aqidah). Di bawah pengawasan Majlis ini Abu Nida membuka sebuah desa model di Wirokerten, Bantul, dimana beliau mendirikan Pesantren al-Turast al-Islami dengan Masjid jamil al-Rahman. Semua kegiatan pesantren dikonsentrasikan di Masjid tersebut, meskipun jumlah santrinya tidak mencapai 50 orang. Mereka belajar membaca buku teks Islam klasik dan modern, khususnya yang terkait dengan paham Wahabi dan gaya hidup salafi. Setelah itu, Abu Nida mendirikan Islamic Center

14 Ibid., hal 46. Lihat juga Suhanah, Gerakan Dakwah Salafi di Indonesia, hal.230-231.

15 Din Wahid, "Nurturing The Salafi Manhaj: A Study of Salafi Pesantrens in Contemporary Indonesia" dalam Disertasi bentuk pdf (Belanda: Universiteit Utrecht, 2014), hal.95.

16 Noorhaidi, Lasykar Jihad, hal.46. 
Bin Baz (ICBB) di Karang Gayam, Sitimulyo, Piyungan, Bantul, Yogyakarta yang mencakup berbagai jenjang sekolah mulai dari TK, SD, SMP, hingga SMA. ${ }^{17}$

Jaringan transnasional salafi tidak lain adalah Timur Tengah, dimana ajaran Salafi masuk ke Indonesia melalui para sarjana alumni Timur Tengah tersebut, terutama mereka yang bersekolah di Universitas-Universitas di Arab Saudi dan Kuwait. Dua negara ini merupakan basis utama atau sentral gerakan salafi seluruh dunia. Selain itu, dua negara kaya minyak ini juga merupakan sumber utama pendanaan bagi kelangsungan aktivitas gerakan salafi. Perkembangan gerakan salafi di Indonesia juga mendapat dukungan langsung melalui kehadiran tokoh-tokoh intelektual Arab di antaranya dari Arab Saudi sendiri, Kuwait dan Yaman. ${ }^{18}$

Penetrasi paham salafi ke Indonesia juga dilakukan melalui pemikiran Muhammad bin Abdul Wahab. Ajaran Salafi masuk ke Indonesia melalui para sarjana alumni Timur Tengah, terutama mereka yang bersekolah di UniversitasUniversitas di Arab Saudi dan Kuwait. Dua negara ini merupakan basis utama atau sentral gerakan Salafi seluruh dunia. Dua negara kaya minyak ini ditengarai sebagai sumber utama pendanaan bagi kelangsungan aktivitas gerakan salafi. Beberapa tahun belakangan, gerakan salafi bermunculan di beberapa daerah di Indonesia seperti terlihat di Jakarta, Yogyakarta, Cileungsi, Bogor, Banten, Batam, Bekasi, Tasikmalaya, Nusa Tenggara Barat, Makasar, Gresik, Solo dan yang lainnya. Terhadap kelompok-kelompok keagamaan transnasional di atas, respon penduduk negeri ini bervariasi. Ada yang apatis, menyambut baik dan ada yang menolak baik secara frontal maupun secara halus. Semua memberikan warna tersendiri bagi perkembangan kehidupan keagamaan di Indonesia. Yang menjadi fokus bersama, masing-masing harus memandang sebagai bagian anak bangsa, menjaga persatuan dan kesatuan sehingga tetap tercipta situasi yang kondusif dan harmonis. ${ }^{19}$

17 Lihat Ibid., hal 48-50. Lihat juga Ahmad Shidqi, Responds Nahdlatul Ulama (NU) Terhadap Wahabisme dan Implikasinya bagi Deradikalisasi Pendidikan Islam, hal.116.

18 Lihat Suhanah, Gerakan Dakwah Salafi di Indonesia, hal.217.

19 Nasaruddin Umar (Wakil Menteri Agama R.I.), “Perkembangan Paham Keagamaan Transnasional di Indonesia" dalam Prolog Perkembangan Paham Keagamaan Transnasional di Indonesia (Jakarta: Kementerian Agama R.I. , Badan Litbang dan Diklat Puslitbang Kehidupan Keagamaan, 2011), hal.xiv-xv. 
Kehadiran gerakan keagamaan transnasional itu, disatu sisi menimbulkan masalah bagi organisasi keagamaan lokal yang telah lama eksis, sementara disisi lain dipandang sebagai gerakan yang mampu memberi harapan baru bagi masa depan umat Islam Indonesia. Sebagian aktifis dan simpatisan organisasi keagamaan lokal, kehadiran gerakan keagamaan transnasional itu dipandang sebagai melengkapi kekurangan-kekurangan yang dimiliki organisasi keagamaan lokal, sebagian lain memandang sebagai bahaya bagi ormas keagamaan lokal, Pancasila, dan Negara Kesatuan Republik Indonesia (NKRI). ${ }^{20}$

\section{Globalisasi Salafi ICBB}

Sebelum membahas tentang globalisasi salafi di ICBB perlu dikemukakan terlebih dahulu tentang pemaknaan nilai-nilai salafi. Kata salafi berasal dari akar kata bahasa Arab: salaf, yaslifu, salafan, yang artinya adalah telah lalu atau lampau. Konteksnya adalah sesuatu yang datang lebih dulu atau sebelumnya. Sedangkan menurut istilah atau makna terminologis, kata salaf merupakan sifat yang khusus dimutlakkan kepada para sahabat Nabi SAW, tabiin dan tabi'i tabiin. Adapun salafi adalah orang-orang yang tetap di atas manhaj kenabian dan menisbatkan diri mereka kepada pendahulu mereka yang shalih yang disebut salaf al-shalih. Atas dasar pemahaman tersebut, salafi berupaya mendakwakan dan mengamalkan Islam secara literal melalui upaya mengembalikan pemahaman tentang Islam kepada pemahaman yang telah digariskan oleh Nabi dan para sahabatnya, sehingga menjadikan salafi sangat kental dengan gagasan purifikasi. ${ }^{21}$

Menurut Yazid bin Abdul Qadir Jawas, salah seorang tokoh salafi, menyebutkan bahwa salafi adalah setiap orang yang berada di atas manhaj salaf dalam aqidah, syariat, akhlak dan dakwah. Secara lebih luas, kata salaf berarti seseorang yang telah mendahului atau terdahulu dalam ilmu, iman, keutamaan dan kebaikan. Salaf menurut istilah adalah sifat yang khusus dimutlakkan kepada para sahabat yaitu orang-orang yang mengikuti para sahabat, tabiin

20 Ibid., hal.220.

21 Lihat Dady Hidayat, "Gerakan DakwahSalafi di Indonesia: Studi Tentang Kemunculan dan Perkembangannya pada Era Reformasi" dalam Skripsi (Jakarta: UI Fakultas Ilmu Sosial dan Ilmu Politik Program Studi Sosiologi, Juni 2012), hal.41. 
dan tabiit tabiin. Kata salaf sering dikaitkan dengan kata ulama, seperti ulama salaf, yang berarti ulama lama sebagai lawan dari ulama baru (khalaf) atau kontemporer. Salafi dalam konteks faham keagamaan adalah penisbatan kelompok orang atau komunitas yang memperaktekkan Islam berdasarkan teks Al-Qur'an dan As-Sunnah sebagaimana yang diamalkan oleh para sahabat Nabi Muhamad SAW. Salafi atau shalafush shaleh adalah para sahabat dari tabiin dan tabiit tabiin. Mereka dianggap sebagai orang-orang yang telah memahami dan mempraktikkan Islam secara benar. Pada era awal perkembangan Islam, salafi bukan faham, aliran apalagi sebuah ideologi. Salafi adalah sebuah praktik keberagamaan yang sangat berbeda dengan praktik keagamaan yang dilakukan oleh kelompok-kelompok seperti Syi'ah, Khawarij, Mu'tazilah, Qodariyah dan Jabariyah. Pemahaman dan praktik keagamaan seperti ini, belakangan diformulasikan dengan istilah ahl al-sunnah wa al-jama'ah. ${ }^{22}$ Walaupun istilah yang terakhir ini lebih dikenal dengan Aswaja (ahl al-sunnah wa al-jama'ah) atau lebih dekat dengan sebutan sunni, namun kaum salafi juga tidak meninggalkan sunnah Nabi, justru menjadikannya sebagai pokok gerakannnya.

Namun demikian, kelompok yang disebut Wahabi tetap mengkalim sebagai pengikut Ibnu Taimiyah sehingga mereka juga menamakan dirinya sebagai salafi. ${ }^{23}$ Secara teologis, sebenarnya tidak ada perbedaan mendasar antara Wahabi dan salafi, bahkan keduanya adalah sama. ${ }^{24}$ Kedua istilah tersebut ibarat dua sisi pada satu keping mata uang. Ketika di Jazirah Arab mereka sering dikenal dengan Wahabiyah Hanabilah. Namun ketika diekspor ke luar Arab Saudi, mereka mengatasnamakan dirinya sebagai salafi, khususnya setelah bergabungnya Muhammad Nashirudiin al-Albani, yang mereka pandang sebagai ahli hadis. Karena itulah kemudian banyak juga yang menyebut mereka ini sebagai salafi-Wahabi. ${ }^{25}$ Penyebutan salafi yang berkembang saat ini sebenarnya untuk memperluas cakupan jaringan, mengingat kata Wahabi

22 Suhanah, "Gerakan Dakwah Salafi di Indonesia: Kasus Aktivitas Dakwah Salafi di Jakarta dan Bogor" dalam Perkembangan Paham Keagamaan Transnasional di Indonesia (Jakarta: Kementerian Agama R.I. , Badan Litbang dan Diklat Puslitbang Kehidupan Keagamaan, 2011), hal.224

${ }_{23}$ Mustafa Kabha and Haggai Erlich, International Journal of Middle East Studies Cambridge University Press Vol. 38, No. 4 (Nov., 2006), hal.524, 528, 530

${ }^{24}$ Hasil interview dengan Abu Nida pada 17 September 2015 di ICBB.

25 Ahmad Shidqi, Responds Nahdlatul Ulama (NU) Terhadap Wahabisme dan Implikasinya bagi Deradikalisasi Pendidikan Islam, hal.113. 
identik dengan ketokohan tertentu, dan bisa jadi kontroversial. Jadi dengan salafi dimaksudkan pemaknaannya lebih umum sekaligus dekat dengan idiom sunni. Selain itu sebutan salafi berkonotasi pada ulama terdahulu, dari mulai sahabat, tabiin dan tabiit tabiin yang diakui oleh banyak kalangan umat Islam sebagai panutan utama.

Dalam Ensiklopedi Islam dan Ensiklopedi Tematis Dunia Islam dijelaskan bahwa gerakan pemikiran Islam salafi adalah gerakan pemikiran yang berusaha menghidupkan kembali atau memurnikan ajaran Islam yang berdasarkan pada Al-Qur'an dan Sunnah Nabi Muhammad SAW, sebagaimana yang telah diamalkan oleh para salaf (para sahabat terdahulu). Tujuan dari gerakan pemikiran salafi adalah agar umat Islam kembali kepada dua sumber utama pemikiran Islam, yakni kitab suci Al-Qur'an dan Sunnah Rasulullah SAW, serta meninggalkan pendapat ulama mazhab yang tidak berlandaskan pada dua sumber ajaran tersebut. Juga memurnikan ajaran Islam dari pengaruh kepercayaan dan tasawuf yang menyesatkan, menghilangkan ajaran tasawuf yang mengkultuskan para ulama dan pemujaan kuburan para wali atau tokoh agama. ${ }^{26}$

DiIndonesia,ide-idegerakan pemikiran salafiberkembang sejakera Kolonial Belanda. Gerakan pemikiran salafi di Indonesia mengalami perkembangan bersamaan dengan munculnya tokoh-tokoh gerakan pemikiran salafi di Timur Tengah (Mesir) seperti Syeikh Jamaluddin al-Afghani (1839-1897), Muhammad Abduh (1849-1905), dan Rasyid Ridha (1865-1935). Para tokoh pembaharuan Mesir ini di samping mengajak ummat Islam untuk "kembali kepada alQur'an dan sunnah Nabi Muhammad saw.", juga mengajak ummat Islam agar meningkatkan ilmu pengetahuan dan teknologi modern untuk mencapai kemajuan, menghilangkan kebodohan, dan mengatasi keterbelakangan. Orang-orang Indonesia yang menunaikan ibadah haji ke Makkah kemudian bermukim di sana memanfaatkan waktunya untuk belajar agama Islam. Setelah pulang secara individu atau melalui organisasi, mereka melakukan gerakan pembaharuan Islam beraliran Salafi. Upaya-upaya yang dilakukan oleh para tokoh gerakan keagamaan tersebut adalah mengajak umat Islam

\footnotetext{
26 Ibid., hal.226.
} 
meninggalkan praktek-praktek keagamaan yang bernuansa bid'ah, khurafat, taqlid, dan mendorong mereka melakukan ijtihad. ${ }^{27}$

Selanjutnya terkait dengan terma globalisasi salafi dapat dijelaskan secara terminologis yaitu: globe artinya dunia, global berarti mendunia, dan globalisasi berarti proses mendunia. Jadi, globalisasi salafi berarti proses menjadikan gerakan salafi mendunia. Globalisasi adalah sebuah istilah yang dikenalkan pertama kali oleh wartawan Theodore Levit pada tahun 1980an. Menurut Mansur Faqih, globalisasi merupakan fase ketiga dari sejarah dominasi dan eksploitasi manusia atas manusia yang lain. Sedang fase pertama adalah kolonialisasi dan fase kedua adalah era pembangunan (developmentalism). Proses globalisasi ditandai dengan pesatnya perkembangan paham kapitalisme, yakni kian terbukanya atau mengglobalnya peran pasar, investasi, dan proses produksi dari perusahaan-perusahaan transnasional yang kemudian dikuatkan oleh ideologi dan tata dunia baru di bawah suatu aturan yang ditetapkan oleh organisasi perdagangan bebas secara global. ${ }^{28}$ Globalisasi ini ibarat gelombang pasang yang merambah dunia hingga di hampir seluruh negara mengalami goncangan atau turbulensi. Turbulensi arus global ini amat kuat dan memberi dampak pada semua aspek kehidupan manusia, termasuk praktik pendidikan Islam dan gerakan salafi di tanah air.

Dalam The Consequences of Modernity (1990), Anthoni Gidden memperkenalkan konsep globalisasi menjadi teori sosialnya yang mendefinisikan globalisasi sebagai proses intensifikasi hubungan sosial antar dunia yang terhubung dari daerah yang berjauhan sedemikian rupa sehingga peristiwa lokal tersebut dibentuk oleh peristiwa yang terjadi bermil-mil jauhnya, dan bergitu pula sebaliknya. Globalisasi menekankan pada kehadiran dan ketiadaan keterkaitan antar peristiwa dan jaringan sosial "pada jarak jauh" dengan konteks lokal. Memang Gidden lemah dalam membahas empat dimensi lembaga modern, yang mencakup: kapitalisme, industrialisme, pengawasan politik negara bangsa, dan kekuatan militer. ${ }^{29}$ Gidden kurang memperhatikan

${ }^{27}$ Faizah, "Pergulatan Teologi Salafi dalam Mainstream Keberagamaan Masyarakat Sasak" dalam Ulumuna, Jurnal Studi Keislaman (Mataram: Fakultas Dakwah IAIN Mataram, 2012), hal.382.

28 Ashad Kusuma Djaya, Teori-Teori Modernisasi dan Globalisasi (Yogyakarta: Kreasi Wacana, 2012), hal.81-82.

29 John Tomlinson, Globalization and Culture (UK: Polity Press and Blackwell Publishers 
masalah budaya, ${ }^{30}$ apalagi bicara soal globalisasi dan modernisasi agama. Yang dijelaskan oleh Gidden adalah bahwa uang merupakan sarana untuk mengangkat (lifting out) hubungan sosial-ekonomi dari ketentuan tempat dan waktu suatu lokal. ${ }^{31}$ Modernitas menurut Gidden, mencabik-cabik ruang jauh dari tempat, sehingga is bisa menumbuhkan hubungan jarak jauh antara masyarakat yang tidak bertemu satu sama lain pada suatu tempat. Di sinilah yang membuat modernitas jadi mengglobal. Peristiwa lokal secara keseluruhan menembus dan membentuk pengaruh sosial yang amat jauh dari tempatnya. ${ }^{32}$

Bagi Gidden, munculnya "masyarakat kosmopolitan global" menimbulkan pertentangan dengan fundamentalisme. Terlebih lagi, fundamentalisme menggunakan kekuatan-kekuatan global, misalnya media massa, untuk mencapai tujuan-tujuannya. Fundamentalisme bisa memiliki beragam bentuk, yaitu agama, etnis, nasionalis, politik, maupun lainnya. Namun, apapun bentuknya, Gidden menganggap benarkalau kitamemandang fundamentalisme sebagai problematika, karena dia berujung pada kemungkinan terjadinya kekerasan, dimana hal itu merupakan musuh bagi nilai-nilai kosmopolitan. ${ }^{33}$

Hadirnya media massa elektronika melalui dunia tanpa kabel, wireless, dan dunia maya, cybernet, telah mengubah gaya mengajar seorang guru atau kiai. Gaya hidup modern ditandai dengan serba canggihnya teknologi, dari teknologi komunikasi hingga transportasi. Tak pelak lagi, globalisasi dipengaruhi oleh perkembangan teknologi. Teknologi mutakhir saat ini telah berkembang pesat yang mencakup teknologi bidang kesehatan, teknologi berbasis ruang, perkembangan bangsa yang dipengaruhi oleh kecanggihan teknologi terdahulu sambil mengadopsi teknologi baru yang lebih canggih, atau disebut Leapfrogging. Juga, hadirnya media global baru semisal Microsoft, Google, Yahoo, dan lainya, atau perkembangan indymedia (independent media) sebagai bentuk lain dari keberagaman media yang mengkonter imperialisme media, seperti gerakan protes anti-globalisasi ketika pertemuan WTO di Seattle pada tahun 1999. Termasuk di antara perkembangan teknologi dimaksud adalah munculnya media global, seperti TV, HP, dan alat elektronik-digital

\footnotetext{
Ltd., 1999), hal 47.

30 Ibid., hal.59.

31 Ibid., hal.55.

32 Ibid., hal.52.

33 Ibid., hal.91-93.
} 
lain yang menciptakan desa-global (global village). Di samping itu, internet merupakan sebagian dari teknologi digital yang berdampak mendalam bagi banyak hal, termasuk globalisasi. Belakangan ini amat digandrungi pula jejaring sosial online yang memberi janji-janji kemajuan lebih luas dalam kemampuan berkomunikasi secara global. ${ }^{34}$

Penting diketahui, bahwa ICBB Yogyakarta juga memanfaatkan perkembangan teknologi untuk kepentingan pendidikan dan dakwah yang dapatmerambahsampai ke pentas global. Di lembaga tersebutdijumpai berbagai fasilitas elektronik semisal komputer dengan internetnya, website, telepon seluler produk terkini, serta media TV, radio, buletin, majalah, dan lainnya. Dengan demikian kedua pesantren tersebut tidaklah anti-modernitas, namun sambil menarik ulur identitasnya agar tidak terseret ke arus modernitas, mereka mampu merembes ke pasar global. Uraian di bawah ini mengetengahkan teori tentang asal muasal lahirnya globalisasi serta bentuk-bentuk globalisasi, yang pada tempatnya akan dianalisis kaitannya dengan dua pesantren tersebut.

Menurut George Ritzer, globalisasi itu tidak hanya terjadi saat ini saja, melainkan sebelumnya juga, dan sekarang telah berkembang kian kuat dan nyata. ${ }^{35}$ Beberapa isu kuat yang mengubah menjadi asal muasal munculnya globalisasi secara kompleks adalah: pertama, apa yang diistilahkan dengan hadrwired atau akar globalisasi yang muncul di antara banyak sebab, dari kebutuhan dasar manusia untuk mencari kehidupan yang lebih baik dan memenuhi kebutuhan. Namun, hardwired ini bukanlah satu-satunya yang diterima oleh manusia karena kita saat ini hidup di abad global yang berbeda, melainkan masih ada beberapa aspek lain dari globalisasi yang terkait dengan "desakan atau kebutuhan" hidup yang lebih baik, yaitu: perdagangan atau komersial, upaya misionaris agama, petualangan dan penaklukan (politik dan perang). Semua itu merupakan aspek kunci globalisasi yang dapat dilacak dalam sejarah manusia awal. ${ }^{36} \mathrm{Kedua}$ adalah siklus (cycle). Globalisasi itu membutuhkan proses siklus jangka panjang, dan justru siklus itulah yang paling penting, bukan fase tertentu atau asal muasal tertentu. Ketiga adalah gelombang globalisasiatau epochs. Keempat, peristiwa (events), misalnya adalah

34 Lihat George Ritzer, Globalization: A Basic Text (USA: Wiley-Blackwell, A John Wiley and Sons, Ltd., Publication, 2010), hal.278-290.

35 George Ritzer, Globalization: A Basic Text, hal.35.

$36 \quad$ Ibid., hal 37. 
peristiwa penyebaran Islam pada abad ke-7 Masehi dan seterusnya. Dan kelima adalah perubahan terkini (more recent changes), misalnya bangkitnya Amerika sebagai kekuatan global pasca Perang Dunia II, ${ }^{37}$ atau bisa juga dalam konteks ini adalah perkembangan terkini dari gerakan salafi.

Jika kelima asal muasal munculnya globalisasi di atas dapat digunakan untuk menganalisis gerakan salafi di ICBB Yogyakarta. ICBB Yogyakarta membentuk hardwired karena kian pesatnya perluasan bangunan, gedung, fasilitas, serta kelembagaan yang ada tentu menjadikan kemakmuran dan kehidupan yang lebih baik bagi komunitasnya. Apalagi bila dilihat dari sisi siklus (cycles) dari perkembangan ICBB Yogyakarta ini masih generasi pertama sejak dirintisnya pada tahun 1993 di bawah kepemimpinan yang sama, yaitu Abu Nida, dan belum dilanjutkan oleh generasi berikutnya.

Agaknya, bila dilihat dari segi ini, ICBB Yogyakarta mampu berkembang lebih pesat, terutama ditinjau dari sisi tahun berdirinya yang relatif baru, generasi kepemimpinannya yang masih dipegang oleh pendiri pertama, grafik jumlah santrinya yang terus meningkat, jenjang pendidikan yang diselenggarakannya, dan ekspansi kelembagaannya yang telah menjangkau ke berbagai kota, serta jaringan komunitasnya yang luas. Hingga kini perwakilan ICBB telah mencakup banyak kota besar di Indonesia, seperti: Siak, Pelelawan, Kota Jambi, Soralangun, Kepahiang, Lubuklinggau, Lampung Utara, Sintang, Pontianak, Palangkaraya, Toli-Toli, Bekasi, Banyumas, Jakarta Barat, Jakarta Pusat, Serang, Tuban, Malang dan Surabaya. ${ }^{38}$ Lebih dari itu, tamu dan pelajar yang datang ke ICBB bukan hanya dari warga sekitar, namun juga dari mancanegara seperti Malaysia, Thailand, Singapore, dan negara Asia Tenggara lainnya. Agar lebih mudahnya memahami asal usul globalisasi pesantren di atas, berikut ini ditampilkan bagannya. 
Bagan 1: Asal Usul Globalisasi Salafi di ICBB

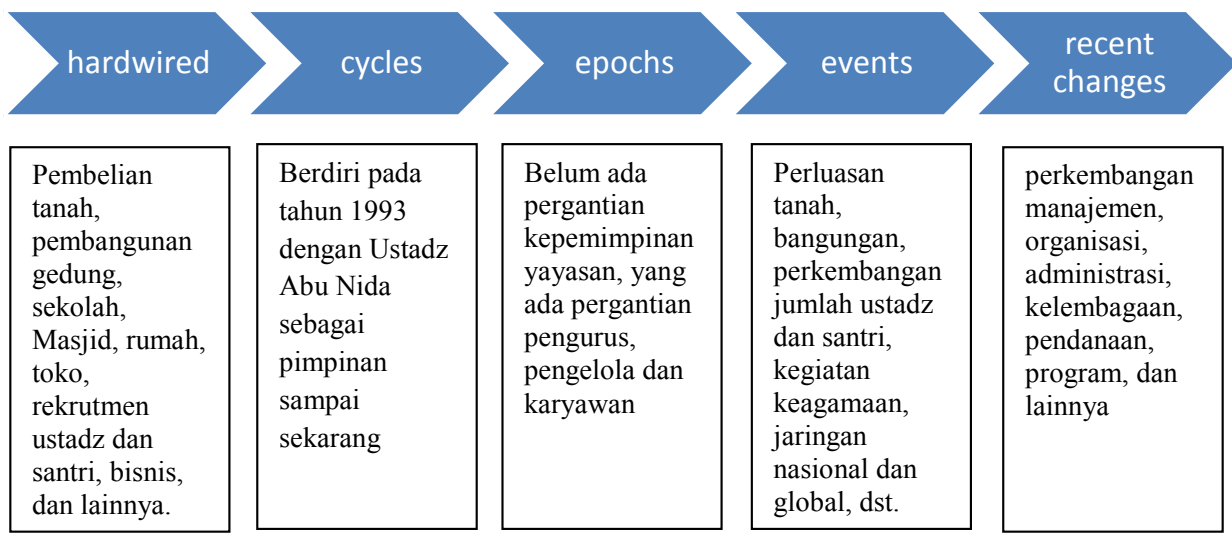

ICBB Yogyakarta mendekatkan diri pada ulama salafi-Wahabi dari Madinah dan Kuwait. Para Ustadz dari Makkah, Madinah, dan Kuwait tadi juga tidak melepaskan jaringan komunikasi alumninya, mereka pada berkunjung ke pesantren, memberi donasi, ceramah umum, dan bahkan bilamana tinggal dalam waktu yang agak lama, mereka pun mengajar di pesantren tersebut. Sebagai contoh, hadirnya Syaikh Muhammad bin Mubarak Asy Syarafi, seorang da'i, imam dan khatib di Arab Saudi yang merupakan murid dari Syaikh Muhammad bin Shalih Al Utsaimin, untuk berdakwah di Yogyakarta, Magelang dan Salatiga mulai 24 sampai 27 Agustus 2015. Safari dakwah ini terselenggara atas kerjasama berbagai organisasi salafi, seperti Yayasan Majelis At Turost Al Islamy, Yayasan Imam Syafi'i Yogyakarta, Yayasan Muslim Merapi Boyolali, Yayasan Islam Al Furqon Magelang, Takmir Masjid Ulil Albab, UII, Islamic Center baitul Muhsinin Yogyakarta, Ponpes ICBB Yogykarta sendiri, Ponpes Hamalatul Qur'an, Ponpes Jamilurrahman Bantul, Pesantren islam Al Irsyad Tengaran, dan Pengajian Muslimah Yogyakarta. ${ }^{39}$ Dari sini dibangun jaringan transnasional gerakan salafi melalui ranah ekonomi, politik, agama, budaya, sains, kesehatan dan pendidikan. Agar lebih jelasnya, bentuk-bentuk globalisasi salafi di ICBB dapat ditampilkan sebagai berikut.

39 Lihat Brosur ICBB dalam www.binbaz.or.id pada tanggal 18 Agustus 2015. 
Bagan 2: Bentuk-Bentuk Globalisasi Salafi di ICBB

\section{Bentuk bentuk Globaliasi Salafi di ICBB}

-Globalisasi ekonomi: adanya dana pribadi, wakaf, sumbangan penyelenggaraan pendidikan (SPP), toko, infaq, zakat, donasi Timur Tengah, dan lainnya

-Globalisasi politik: berpegang pada Qur'an-Hadis secara literer, berasas syari'ah, namun mengharamkan politik dan tidak anti-Pemerintah yang sedang berkuasa

- Globalisasi agama dan budaya: sebagian putra berpakaian gamis putih, sering berwarna, kadang tanpa sorban, kadang pakai peci hitam, celana panjang di atas mata kaki, dan bagi perempuan umumnya warna gelap, bercadar. Merujuk pada ibn Taimiyah, Abdul Wahab (Wahabi), Bin Baz, Utsaimin, dst. Anti-syi'ah, anti-filsafat, anti-tasawuf, dan anti-bid'ah

-Globalisasi Sains dan Kesehatan: mendirikan STIKES, Radio Rodja, website, olah raga bela diri dst. Anti budaya Barat, tapi tidak anti-modernitas dan memakai media global

-Globalisasi pendidikan: dakwah dan pendidikan bercabang di seluruh Indonesia. Mempunyai jenjang TK sampai PT, dan kerjasama dengan Universitas di Saudi Arabia dan Kuwait

ICBB Yogyakarta termasuk di antara lembaga pendidikan Islam yang elastis dalam menghadapi arus global dan modernisasi. Di tengah derasnya pengaruh asing, produk budaya Barat dan Eropa dengan gaya hidup yang liberal, kedua lembaga tersebut di satu sisi mampu menarik atau menerima kehidupan modern dalam bentuk yang disesuaikan dengan kebutuhan pendidikan Islam. Contohnya adalah pemanfaatan alat komunikasi seperti $\mathrm{Hp}$, internet, dan multimedia dengan perangkat komputer, alat-alat elektronik dan produk digital lainnya dalam keseluruhan proses pendidikan, manajemen dan administrasi. Teknologi Informasi dan Komunikasi tersebut telah masuk menjadi bagian dalam aktivitas pendidikan Islam di ICBB Yogyakarta, proses pembelajaran di kelas, pendataan, registrasi, publikasi, dan sebagainya. Bahkan kedua lembaga tersebut telah membuka laman, link dan website sendiri yang isinya memuat banyak informasi tentang kegiatan pendidikan Islam di lembaganya secara lengkap.

Namun di sisi lain lembaga dimaksud mengulur atau menolak masuknya pengaruh global dan modernitas yang "asing" terutama dalam aspek dinamika sosial-budaya, pendidikan dan politik. Misalnya, cara berpakaian, adab makan, pergaulan, etika komunikasi, dan seterusnya. Bagi ICBB Yogyakarta, etika berpakaian pimpinan, para ustadz dan santri berlengan panjang dengan baju yang mendekati batas lutut, serta celana panjang sampai mata kaki.Sebagai penutup kepala mereka banyak menggunakan kopyah hitam, namun banyak juga yang tanpa kopyah, termasuk pimpinannya ICBB.Janggut tetap menjadi 
ciri khas komunitas ini, dan penerapan seragam tersebut telah diatur dalam tata tertib lembaga. Pondok putri lokasinya terpisah dengan putra, namun ibuibu wali santri terlihat keluar-masuk dengan kendaraan motor di lingkungan pondok putra, dimana mereka meskipun berbusana muslimah dan jilbab, namun wajah, pergelangan tangan dan kaki tidak ditutup dengan kaos atau sarung. Dengan letak georafis yang berada di wilayah kecamatan dan dikelilingi oleh masyarakat, sekolah, pasar, sentra bisnis, dan kantor kelurahan dan kecamatan, maka interaksi sosial para ustadz dan santri di ICBB Yogyakarta ini menjadi terbuka, apalagi tidak semua santri yang belajar tinggal di asrama atau pondok.

Dari uraian di atas jelaslah bahwa secara teknologis, ICBB dapat beradaptasi dan menerima perkembangan modern dan pengaruh global, namun dari sisi lain nilai-nilai keagamaan dan tradisi lokal kepesantrenan tetap dipelihara dengan baik menurut kecenderungan paham dan ideologinya masing-masing. Ini sejalan dengan adagium yang dianut oleh mayoritas pesantren, yaitu memelihara nilai-nilai lama yang baik dan mengambil nilai-nilai baru yang lebih baik, al-muhafadah ala al-qadim al-shalih wa al-akhdzu bi al-jadid al-ashlah.

\section{E. Penutup}

Karakter agama Islam sejak semula cenderung global. Gerakan dakwah dan pendidikanlah yang mempercepat proses global dari agama tersebut. Namun demikian, tidak semua gerakan keagamaan Islam mengikuti sepenuhnya terhadap arus global dan modernisasi. Bisa jadi bagi gerakan keagamaan Islam yang modernis lebih banyak menyerap kemajuan zaman, namun bagi gerakan Salafi, tidak semua dampak global dan modernisasi diterima. Kemajuan teknologi informasi dan komunikasi merupakan produk kemajuan zaman yang dipandang netral, value-free, dan diserap oleh gerakan Salafi justru untuk menyebarkan nilai-nilai dan ideologinya. Namun, budaya asing dan etika sosial Barat yang dianggap bersebrangan dengan nilai-nilai Islami, semisal etika pergaulan, berpakaian, pola makan, dan sebagainya, tidaklah diambil, dan sebaliknya gerakan Salafi tersebut back to basic pada ajaran Islam yang murni.

Gerakan transnasional Salafi perlu dicermati secara teliti agar tidak terjebak pada pemaknaan yang salah terhadap terma-terma tertentu yang secara 
sosio-historis bukan muncul dari peristilahan dunia Islam. Jika gerakan Salafi diidentikkan dengan fundamentalisme, radikalisme, maupun terorisme, maka secara faktual selain hal itu bisa terjadi pada gerakan agama manapun di dunia ini, juga tidak terjadi di lingkungan pondok pesantren yang diteliti, mengingat fundamentalisme, radikalisme dan terorisme telah bercampur dengan unsurunsur politik yang lebih kuat dari pada agama.

Madrasah Diniyah al-Bakriyah Kelantan dan ICBB Yogyakarta memiliki ciri masing-masing dalam pola gerakan Salaf dan Salafi, serta daya tahan terhadap modernitas dan globalisasi. Di era digital ini tidak dapat dihindari lagi munculnya arus globalisasi gerakan tersebut yang berskala transnasional. Di bagian manakah gerakan tersebut membawa kontribusi bagi dunia Islam, adalah tergantung dari nilai-nilai gerakannya itu sendiri. Wallahu A'lam bi alShawab.

\section{F. DAFTAR PUSTAKA}

Abd Rachman Assegaf. 2011.Filsafat Pendidikan Islam: Paradigma Baru Pendidikan Hadhari Berbasis Integratif-Interkonektif. Jakarta: PT RadjaGrafindo Persada.

Ahmad Shidqi. 2012. Responds Nahdlatul Ulama (NU) Terhadap Wahabisme dan Implikasinya bagi Deradikalisasi Pendidikan Islam" dalam Jurnal Pendidikan Islam. Yogyakarta: STAI Sunan Pandanaran.

Ashad Kusuma Djaya. 2012.Teori-Teori Modernisasi dan Globalisasi. Yogyakarta: Kreasi Wacana.

Azyumardi Azra. 2009. "Muhammadiyah: Tantangan Islam Transnasional" dalamMaarif: Arus Pemikiran Islam dan Sosial,100TahunMuhammadiyah: Civil Society dan Tantangan Gerakan Islam Transnasional. Yogyakarta: Maarif, Vol.4 No.2.

Dady Hidayat. 2012. “Gerakan Dakwah Salafi di Indonesia: Studi Tentang Kemunculan dan Perkembangannya pada Era Reformasi" dalam Skripsi. Jakarta: UI Fakultas Ilmu Sosial dan Ilmu Politik Program Studi Sosiologi, Juni.

Din Wahid. 2014. “Nurturing The Salafi Manhaj: A Study of Salafi Pesantrens in Contemporary Indonesia" dalam Disertasi bentuk pdf . Belanda: Universiteit Utrecht. 
Erfanto Linakung. 2015. "Perluasan ICBB Ditolak Warga Piyunyan" dalam Koran Sindo, Senin 28 September 2015.

Faizah. 2012. "Pergulatan Teologi Salafi dalam Mainstream Keberagamaan Masyarakat Sasak" dalam Ulumuna, Jurnal Studi Keislaman (Mataram: Fakultas Dakwah IAIN Mataram.

ICBB. 2012. Fatawa Volume VI Nomor 07 s/ d Nomor 11 Tahun 2012.

Kabha, Mustafa and Haggai Erlich. 2006. International Journal of Middle East Studies Cambridge University Press Vol. 38, No. 4.

M Hilaly Basya. 2009. "Muhammadiyah, Salafi dan Demokrasi: Studi Respon Cendikiawan Muhammadiyah Terhadap Gerakan Islam Transnasional" dalam Maarif: Arus Pemikiran Islam dan Sosial, 100 Tahun Muhammadiyah: Civil Society dan Tantangan Gerakan Islam Transnasional. Yogyakarta: Maarif, Vol.4 No.2.

Mastuhu. 2003. Menata Ulang Pemikiran Sistem Pendidikan Nasional dalam Abad 21. Yogyakarta:Safiria Insania Press.

Nasaruddin Umar (Wakil Menteri Agama R.I.). 2011. “Perkembangan Paham Keagamaan Transnasional di Indonesia" dalam Prolog Perkembangan Paham Keagamaan Transnasional di Indonesia (Jakarta: Kementerian Agama R.I., Badan Litbang dan Diklat Puslitbang Kehidupan Keagamaan.

Noorhaidi Hasan. 2005. Lasykar Jihad: Islam, "Militancy and the Quest for Identity in Post New Order Indonesia" dalam Disertasi dalam bentuk pdf. Belanda: Universiteit Utrecht.

Ritzer, George. 2010. Globalization: A Basic Text. USA: Wiley-Blackwell, A John Wiley and Sons, Ltd., Publication.

Sudarwan Danim. 2003. Agenda Pembaruan Sistem Pendidikan. Yogyakarta: Pustaka Pelajar.

Suhanah. 2011. "Gerakan Dakwah Salafi di Indonesia: Kasus Aktivitas Dakwah Salafi di Jakarta dan Bogor" dalam Perkembangan Paham Keagamaan Transnasional di Indonesia. Jakarta: Kementerian Agama R.I. Badan Litbang dan Diklat Puslitbang Kehidupan Keagamaan.

Tomlinson, John. 1999. Globalization and Culture. UK: Polity Press and Blackwell Publishers Ltd. 
172 Millah Vol. XVI, No. 2, Februari 2017

\section{Internet}

www.binbaz.or.id

www.wikipedia.org

\section{Interview dan Observasi}

Turino, pada Kamis 17 September 2015 di kantor bagian informasi ICBB. Abu Nida, pada Kamis 17 September 2015 di ICBB. 